Chapter 9

\title{
How Plasma Membrane and Cytoskeletal Dynamics Influence Single-Cell Wound Healing: Mechanotransduction, Tension and Tensegrity
}

\author{
Eric Boucher, Tatsuya Kato and Craig A. Mandato
}

Additional information is available at the end of the chapter

http://dx.doi.org/10.5772/63765

\begin{abstract}
Organisms are able to recover from injuries by replacing damaged tissues, which recover by replacing damaged cells and extracellular structures. Similarly, a cell recovers from injuries by replacing damaged components of its structural integrity: its plasma membrane and cytoskeletal structures. Cells can be thought of as tensegral structures, their structural integrity relying on the interplay between tensile forces generated within and without the cell, and the compressive elements that counteracts them. As such, direct or indirect insults to the plasma membrane or cytoskeleton of a cell may not only result in the temporary loss of structural integrity, but also directly impact its ability to respond to its environment. This chapter will focus on the various aspects linking tensile forces and single-cell wound healing: where and how are they generated, how does the cell counteract them and how does the cell return to its previous tensegrity state? These questions will be explored using ubiquitous and cell-type specific examples of singlecell repair processes. Special attention will be given to changes in plasma membrane composition and area to cytoskeletal dynamics, and how these factor each other to influence and effect single-cell repair.
\end{abstract}

Keywords: single-cell wound healing, tensegrity, plasmalemma dynamics, cytoskeleton dynamics, mechanotransduction

\section{Introduction}

Cells are neither amorphous blobs nor rigid, unchanging structures. They are able to sense, react and most of the time recover from many types of physical insults ranging from pores 
created by osmotic shock or bacterial toxins to mechanical damages of various origins and intensity. Whatever the origin, the loss of barrier function provided by the plasmalemma leads to many potentially harmful effects including, but not limited to, the loss of intracellular content, the uncontrolled entry of $\mathrm{Ca}^{2+}$ and exposure of the intracellular milieu to reactive oxygen species (ROS), all of which may lead to a broad range of diminished cellular function, or even cell death. The negative effects of cellular injury are not limited to biochemical processes, they also directly affect the cell's structural integrity. As such, single-cell repair is as much a return to normal cell function as it is a return to structural integrity.

While they share common general steps of wound stabilization, resealing of plasmalemma damage and cytoskeletal remodeling, wound-healing mechanisms have been shown to vary widely according to the types of injury and cell-types. This chapter, using ubiquitous and injury- and cell-specific examples, aims to present an overview of the different mechanisms proposed for wound healing. Particular focus is put on how mechanotransduction, tension and tensegrity influences single-cell wound healing.

\section{Background}

\subsection{Cells are tensegral structures}

In eukaryotic cells, structural integrity is achieved and maintained through tensegrity [1], a term originally coined by the architect R. Buckminster Fuller as a portmanteau of "tensile integrity." Tensegrity describes stable structures achieved through prestress and the interaction of opposing stretch and compression elements [2]. In the cell, cytoskeletal actin filaments act as the main stretch-generating elements and microtubules are the main compression-bearing elements [3]. The role of intermediate filaments is not as well defined, as vimentin has been suggested to act principally as a major component that allows chondrocytes to withstand compressive loading, its contribution to the regulation of cytoskeletal tension and elastic modulus being relatively minor [4,5]. While tensegrity is mainly achieved through these cytoskeletal elements, the plasma membrane has also been shown to play a key role in the cell's tensegrity [6]. Indeed, the composition and shape of the plasma membrane [7, 8], its intrinsic in-plane tension and membrane-to-cortex attachments (MCAs) [6] and the various external forces that may act on a cell's plasma membrane [9-11] have all been suggested to contribute to cellular tensegrity. The terminology surrounding these forces can be somewhat opaque and as such are defined in greater detail in Figure 1.

\subsection{Plasma membrane disruptions, tensegrity and spontaneous repair}

Early observations of lipid bilayers [12], liposomes [13] and erythrocyte ghosts [14] have shown that resealing of small lesions $(<1 \mathrm{~nm})$ are thermodynamically favored events [14]. Disruption of lipid membranes leads to the loss of barrier function of the plasma membrane, which may lead to uncontrolled changes in osmolality and hydrostatic pressure. These changes may be sufficient to alter the wounded cell's apparent membrane tension and thus its tensegrity state [11]. 


\section{Apparent membrane tension}

The force required to effectively deform liposomal membranes has historically been referred simply as "membrane tension". The plasma membrane of cells also contains relatively high amounts of proteins that specifically or non-specifically link them to cytoskeletal structures and therefore require higher amounts of energy to deform than lipid vesicles. As such, it is more accurate to use "apparent membrane tension" in the case of cells since it is the sum of the tensile forces produced by the intrinsic in-plane tension and the membrane-to-cortex attachments (MCAs).

\section{a. In-plane tension of the plasma membrane}

In-plane tension of the plasma membrane is generated by the osmotically controlled difference in hydrostatic pressures between the cytosol and extracellular fluid directly acting on the plasmalemma $[11,12]$ and on the attached cytoskeleton [13]. In-plane tension is thus a factor of the mechanical and viscoelastic properties of the plasmalemma and can be influenced by variations in plasmalemma area $[12,14]$, shape $[7,8,15]$ and composition $[7,16]$.

\section{b. Membrane-to-cortex attachments (MCAs).}

In eukaryotic cells, adhesion between the plasma membrane and the relatively stiffer cortical cytoskeleton significantly contributes to a cell's apparent membrane tension [17]. Whereas in-plane tension is usually considered to be uniform across the membrane, MCA is able to vary across the cell surface, thereby creating areas of high and low apparent membrane tension in polarized cells [18], as well as membrane blebs in areas of low MCA. The specifics of MCA regulations are still unclear, but involves several membrane associated proteins such as filamin, spectrin, ankyrin, and affixin, as well as involving inner leaflet PIP2, as it is known to bind to or affects a great number of actin binding and remodeling proteins such as MARCKS, cofilin, profilin, gelsolin, vinculin, talin, a-actinin, WASP, Arp $2 / 3$, and the Rho family of GTPases (reviewed in [19]).

\section{c. Focal adhesions and Stress-fibers}

External parameters such as the forces generated via cell-matrix adhesion are partly mediated by integrins, a group of heterodimeric transmembrane proteins that bind a variety of extra-cellular matrix (ECM) proteins. Integrins connect to the actin cytoskeleton via numerous intracellular linker proteins such as talin and vinculin. Uneven distribution of these adhesion complexes into "focal adhesions" can therefore influence cytoskeletal and apparent membrane tension, but their assembly and disassembly can also induce variations in apparent membrane tension. Indeed, focal adhesions [20,21] and stress fibers [22] can act as mechanosensors and induce actin depolymerization through a variety of processes including mechanosensitive ion channels, RhoA signaling or directly via F-actin and cofilin (reviewed in [20]).

Figure 1. Tensile forces in the unwounded cell.

Immediately following its disruption, the plasma membrane also loses its asymmetry [15] and individual membrane phospholipids become disordered around the wound edge, which creates edge tension [16]. Indeed, plasma membrane damage directly alters the membrane composition, shape, and its physical properties. Mechanical damage also exposes hydrophobic domains of phospholipid molecules to the comparatively aqueous environment of the newly formed wound edge, which in turn creates a difference in chemical potential between the phospholipids of the wound edge and those of the planar membrane [13]. It is this so-called edge tension [16] that along with the line tension [17] present on the wound edge, provides the driving force necessary for the lateral movement of phospholipids $[18,19]$ and spontaneous resealing of phospholipid membranes. Rates of spontaneous resealing of these relatively simple systems have been shown to depend on a variety of factors that also affect single-cell wound healing: bilayer composition [19], $\mathrm{Ca}^{2+}$ concentration [20] and disruption radius [13]. On the contrary, liposomes, erythrocytes and erythrocyte ghosts membranes are associated with a variety of proteins such as spectrin, which diminish overall phospholipid lateral movement and lead to high tension at the wound edge [21]. As such, neither large liposomes, 
nor erythrocyte ghosts possess the machinery necessary to actively respond to the dramatic loss of tensegrity and changes in localized tensions that are created by large membrane disruption. Consequently, large erythrocyte ghosts' wounds do not spontaneously reseal under physiological conditions [14]. This has been attributed to a number of factors, including the presence of strong MCAs [19] and the lack of endomembranes [22] (Figure 1).

Finally, plasma membrane disruption also exposes the cell to high levels of ROS and $\mathrm{Ca}^{2+}$ ions, either of which can be detrimental to normal cell function. Numerous pathways involving membrane dynamics such as the capacitation [23] and acrosomal reaction [24] steps of sperm maturation (reviewed in [25]) involve $\mathrm{Ca}^{2+}$-dependent signaling. Exocytosis events, such as surfactant secretion [26-28], as well as neuroendocrine [29], synapses [30-32] and auditory cells exocytosis $[33,34]$, are similarly $\mathrm{Ca}^{2+}$ dependent. These events are mediated by a variety of $\mathrm{Ca}^{2+}$-binding proteins such as calpains, annexins and synaptotagmins. Unsurprisingly, the uncontrolled $\mathrm{Ca}^{2+}$ entry that accompanies plasma membrane damage has been shown to activate the same families of $\mathrm{Ca}^{2+}$-binding proteins (reviewed in [35]). The downstream effects of $\mathrm{Ca}^{2+}$ entry will eventually lead to an overall diminution of apparent membrane tension.

\section{Early events of single-cell wound healing are mechanically driven processes}

Single-cell repair proper is an active process, requiring dynamic and concerted manipulations of the cell's membrane and cytoskeletal compartments. Most of these processes, however, take place relatively late following injury or are dependent on preliminary disruption of cytoskeletal structures. In this subchapter, we present the principal wound mitigation events that are activated in the moments immediately following injury and facilitate the subsequent exocytosis-, endocytosis- or membrane-shedding-mediated wound-healing processes.

\subsection{Caveolae-mediated decrease of in-plane membrane tension}

Caveolae are plasma membrane invaginations with a diameter of $50-80 \mathrm{~nm}$ and specific flasklike morphology [36]. Caveolae have long been known to flatten in response to mechanically induced membrane deformation stretch [37]. Indeed, the preincubation of cells with methyl$\beta$-cyclodextrin diminishes the time to cell lysis upon hypotonic challenge [38]. Methyl- $\beta$ cyclodextrin is a cholesterol-depleting compound that has also been shown to severely reduce the number of caveolae at the cell surface [39], probably by limiting the recruitment of caveolin oligomers to the plasma membrane. Caveolae can thus be viewed as a "membrane buffer" that limits injury-induced increases in apparent membrane tension by diminishing the in-plane tension without the need of additional membrane components from $\mathrm{Ca}^{2+}$-dependent exocytosis (Figure 1). Instead, additional membrane area is produced by the rapid flattening and disassembling of caveolae upon mechanical stress, which are rapidly reassembled upon mechanical stress release [40].

The exact molecular events leading to caveolae assembly and disassembly is still somewhat unclear, the specifics of which go beyond the scope of this chapter. Briefly, their assembly is 
initiated by the clustering and further recruitment of phosphatidylinositol 4,5-bisphosphate $\left(\mathrm{PIP}_{2}\right)$, phosphatidylserine (PS) and cholesterol with caveolin oligomers. Recruitment of various cavins oligomers will further increase the local concentration of negatively charged lipid, which in turn nucleates membrane curvature and formation of caveolae structure by the way of electrostatic cavins-cavins or cavins-membrane interactions (reviewed in [41, 42]).

While caveolin-3-deficient mice exhibit robust muscular degeneration [43], the relative contribution of caveolae in protection against stretch-induced mechanical deformation is therefore difficult to judge. An attractive, albeit speculative, hypothesis is that caveolae are involved in both wound prevention and healing. Firstly, they can act as a membrane reserve that buffers the cell against local or global increases in in-plane membrane tension. Secondly, they can passively potentiate plasma membrane repair by releasing apparent membrane tension near the wound edge, a site of initial high membrane tension because of both high line tension and MCA-related tether forces. Finally, caveolae are also known to play central roles in dysferlin-mediated exocytosis (see Section 4.1.3.1) and the endocytic removal of bacterial pores ([44, 45]; see Section 4.2.1) and small mechanical lesions ([45]; see Section 4.1.3.2).

\subsection{Protein array-mediated wound site stabilization}

Most of the wound-healing mechanisms described to date (see Section 4) require a substantial lowering of apparent membrane tension. This is achieved in a number of ways, including the disruptions of MCAs through both $\mathrm{Ca}^{2+}$-dependent and $\mathrm{Ca}^{2+}$-independent membrane repair mechanisms (see Section 4). These $\mathrm{Ca}^{2+}$ - and mechanosensor-mediated disruption of the MCAs and cytoskeletons have been shown to occur in large areas surrounding the wounds or throughout the cell and therefore only help to stabilize the wound indirectly.

The annexins form a large family of $\mathrm{Ca}^{2+}$-sensitive, negatively charged phospholipid-binding proteins (reviewed in [46]). Upon wounding, annexin V translocate to the internal leaflet of the damaged membrane where it binds to the newly exposed phosphatidylserine residues on the wound edge and self-assembles into two-dimensional (2D) arrays [47]. These arrays have been shown to be able to cluster phospholipids, thereby reducing the lateral diffusion of phospholipids [48]. As such, these arrays may help stabilize the wound site until the apparent membrane tension has sufficiently been lowered by other wound-healing mechanisms (reviewed in [35]; see Section 3.1) Indeed, laser ablation experiments performed on murine perivascular cells have shown that the formation of annexin $V$ arrays was necessary for normal wound healing and cell survival [49]. Similar wound stabilization arrays have also been proposed to involve mitsugumin 53 (MG53) oligomers, mini-dysferlinC72 and caveolins [50].

\subsection{Cytoskeletal and MCA dynamics and wound healing}

The cytoskeleton constitutes a substantial component of apparent membrane tension in eukaryotic cells through MCAs (Figure 1). Consequently, cortical cytoskeleton dynamics can also reduce apparent membrane tension and constitutes an important preliminary step of single-cell wound healing. Indeed, actin destabilization has been demonstrated to enhance 
active membrane resealing in a variety of cell types, including 3T3 fibroblasts [51], septal neurons [52] and RGM1 gastric epithelial cells [53].

\subsubsection{Direct and indirect regulation of single-cell injury by cytoskeleton dynamics}

Considering actin's importance for wound healing, it is not surprising that cellular injury affects actin dynamics in several ways. Changes of tensegrity experienced by damaged cells may lead to cytoskeletal remodeling either directly or through mechanotransductive signals. Indeed, sonoporation experiments showed that disruptions of existent plasmalemmal and adjacent cytoskeletal structures were enough to elicit a sustained and broad secondary disruption of the actin cytoskeleton [54]. As previously stated, actin filament bundles are the main providers of tensile forces necessary for a cell's tensegrity ([1]; Figure 1). Cells usually respond to external changes in tensile forces by modulating the sizes, numbers and distributions of F-actin and stress fibers in order to preserve mechanical homeostasis (reviewed in [55]). This is exemplified by experiments performed on endothelial cells [56] and osteoblasts [57] in which compression-induced stress fiber collapse through buckling, followed by actin disassembly events [56,58]. Computer-assisted modeling strongly suggests that the loss of tensile force within the actin fiber upon its buckling is sufficient to induce actin disassembly $[59,60]$. Whether a similar phenomenon contributes to actin fiber disassembly following mechanical damage is intriguing, as it would mean that actin filaments are able to act as their own mechanosensor. Indeed, a series of experiments showed that the tension state of individual actin filaments were inversely proportional to the binding affinity and actin filament-severing activity of cofilin [61-63]. Cofilin is an actin-binding protein that is known to accelerate actin depolymerization at the pointed end, which is also able to sever F-actin [64, 65]. This type of mechanosensing is especially attractive in the context of single-cell wound healing, as it is more sensitive and could induce downstream signals much faster than other traditional mechanosensors such as mechanosensitive ion channels [66], integrins, talin, or other F-actin-localized mechanosensors (reviewed in [62]).

Aside from mechanically related disruptions, cortical and cytoskeletal actin filaments are also disrupted in a variety of $\mathrm{Ca}^{2+}$-dependent manners. Indeed, permeabilization of cells by bacterial pores, such as streptolysin $\mathrm{O}$ (SLO), leads to an increase in intracellular $\mathrm{Ca}^{2+}$ without substantial direct damage to the plasmalemma or subjacent actin cytoskeleton and also incites actin depolymerization [67]. While $\mathrm{Ca}^{2+}$ is able to disrupt actin filaments on its own [68, 69], the effect of $\mathrm{Ca}^{2+}$ on the disruption of normal cytoskeletal architecture is probably best exemplified by its activation of calpains. Calpains are $\mathrm{Ca}^{2+}$-dependent, intracellular cysteine proteases that are known for their relative specificity [70]. Among others, calpains have been shown to cleave talin [71] into a large globular head domain that directly binds integrins, $\mathrm{PIP}_{2}$ and focal adhesion kinases, and a rod domain that binds vinculin and actin. Its degradation by calpains upon wounding would therefore be compatible with the cytoskeletal remodeling that follows membrane disruptions. 


\subsubsection{Cytoskeletal dynamics is at the center of single-cell wound healing processes}

Aside from its role in reducing apparent membrane tension, cytoskeleton remodeling is further required for single-cell wound healing as several plasma-resealing processes involve exocytosis of various vesicles such as lysosomes, MG53-positive vesicles and AHNAK-positive vesicles (reviewed in [35]; see Sections 4.1.2 and 4.1.3.1). As such, these intracellular vesicles must undergo actin- or microtubule-mediated transport to the wound site. An intact cortical cytoskeleton would therefore hinder not only transport and fusion of these vesicles, but also the subsequent removal of the damaged portions of the plasma membrane through endocytosis, blebbing or membrane-shedding processes. However, it should be noted that active repair mechanisms, such as exocytosis, cannot occur with just a minimal actin structure [67]. Reorganization of the cytoskeleton needs to be balanced in such a way that vesicles from intracellular pools are able to cross the actin barrier layer [53], then undergo docking to the wound site facilitated by remaining actin filaments [72] and the kinesin and myosin motor proteins [73].

\section{Archetypes of single-cell repair: influence of injury type and cell type}

As previously stated, disruptions of the plasma membrane or cytoskeletal structures may lead to local or global increases in apparent membrane tension that prohibits spontaneous resealing to occur. Furthermore, plasma membrane damage can be accompanied by direct or indirect disruptions of the cytoskeleton, which worsen the damaged cell structural integrity. In contrast, plasma membrane disruptions generated by pore-forming toxins (PFTs) have little to no immediate impact on local in-plane membrane tension. As such, $\mathrm{Ca}^{2+}$-mediated exocytosis (see Section 4.1.2) and cytoskeletal remodeling (see Section 3.3) and cell-type (Table 1) may have profoundly different impacts depending on the type and size of the injury and may determine the healing pathway that is available to the cell (Figure 2) (reviewed in [35, 74]). Indeed, while uncontrolled entry of $\mathrm{Ca}^{2+}$ is a hallmark of all injury types, its intensity and distribution, together with the nature and size of the wound, as well as tissular context may control how the wound is repaired (Figure 2). The following section aims to present each wound-healing processes in the cellular context of which they were first identified. As it will become apparent in the next subsection, some processes, such as exocytosis, are quasi-ubiquitous, albeit with slight variations in vesicle species or molecular players involved. On the other hand, other processes, such as ESCRT-mediated membrane shedding (see Section 4.2.2) seem to be heavily dependent on wound size.

\begin{tabular}{llll}
\hline Cell type & $\begin{array}{l}\text { Repair } \\
\text { mechanism }\end{array}$ & $\begin{array}{l}\text { Experimental } \\
\text { wound type(s) }\end{array}$ & $\begin{array}{l}\text { Major molecular } \\
\text { players }\end{array}$ \\
\hline $\begin{array}{l}\text { Germ cells } \\
\text { Oocytes }\end{array}$ & $\begin{array}{l}\text { "Membrane } \\
\text { patch" } \\
\text { formation }\end{array}$ & $\begin{array}{l}\text { Mechanical } \\
\text { wounding; }\end{array}$ & Yolk granules; \\
& laser wounding & syntaxins; SNAP-25 75]
\end{tabular}




\begin{tabular}{|c|c|c|c|c|}
\hline Cell type & $\begin{array}{l}\text { Repair } \\
\text { mechanism }\end{array}$ & $\begin{array}{l}\text { Experimental } \\
\text { wound type(s) }\end{array}$ & $\begin{array}{l}\text { Major molecular } \\
\text { players }\end{array}$ & Reference(s) \\
\hline & $\begin{array}{l}\text { Synaptotagmin- } \\
\text { mediated } \\
\text { exocytosis and } \\
\text { "vertex } \\
\text { fusion" }\end{array}$ & $\begin{array}{l}\text { Mechanical } \\
\text { wounding; } \\
\text { laser wounding }\end{array}$ & $\begin{array}{l}\text { Yolk granules; } \\
\text { synaptobrevin; } \\
\text { synaptotagmin } \\
\text { VII; SNAP-25 }\end{array}$ & [76-82] \\
\hline & $\begin{array}{l}\text { Actomyosin } \\
\text { contractile ring }\end{array}$ & $\begin{array}{l}\text { Mechanical } \\
\text { wounding; } \\
\text { laser wounding }\end{array}$ & $\begin{array}{l}\text { RhoA; Cdc42; } \\
\text { F-actin; myosin } \\
\text { II; microtubules }\end{array}$ & [83-89] \\
\hline \multicolumn{5}{|l|}{ Somatic cells } \\
\hline \multirow[t]{2}{*}{$\begin{array}{l}\text { Neuronal } \\
\text { cells }\end{array}$} & $\begin{array}{l}\text { Synaptotagmin- } \\
\text { mediated } \\
\text { exocytosis }\end{array}$ & $\begin{array}{l}\text { Axon } \\
\text { transection }\end{array}$ & $\begin{array}{l}\text { Lysosomes; } \\
\text { synaptotagmin I; } \\
\text { syntaxin I; }\end{array}$ & {$[90,91]$} \\
\hline & $\begin{array}{l}\text { Calpain- } \\
\text { mediated } \\
\text { vesicle fusion }\end{array}$ & Axon transection & Calpains & {$[52,92-94]$} \\
\hline \multirow[t]{3}{*}{ Fibroblasts } & $\begin{array}{l}\text { Synaptotagmin- } \\
\text { mediated } \\
\text { exocytosis }\end{array}$ & $\begin{array}{l}\text { Mechanical } \\
\text { wounding }\end{array}$ & $\begin{array}{l}\text { Lysosomes; } \\
\text { synaptotagmin I; } \\
\text { Synaptotagmin VII; } \\
\text { VAMP-7; Syntaxin-4; } \\
\text { SNAP-23 }\end{array}$ & {$[76,77,95]$} \\
\hline & $\begin{array}{l}\text { Facilitated } \\
\text { resealing }\end{array}$ & Laser wounding & $\begin{array}{l}\text { Predocked TGN- } \\
\text { vesicles; myosin } \\
\text { IIA; PKC }\end{array}$ & {$[51,96-98]$} \\
\hline & $\begin{array}{l}\text { Potentiated } \\
\text { resealing }\end{array}$ & Laser wounding & PKG; CREB & [99] \\
\hline \multirow[t]{2}{*}{ Muscle cells } & $\begin{array}{l}\text { "Membrane } \\
\text { patch" } \\
\text { formation; } \\
\text { Dysferlin- } \\
\text { mediated } \\
\text { exocytosis }\end{array}$ & $\begin{array}{l}\text { Mechanical } \\
\text { wounding; } \\
\text { laser wounding }\end{array}$ & $\begin{array}{l}\text { Lysosomes; } \\
\text { calpains; } \\
\text { mini-dysferlinC72; } \\
\text { MG53; KIF5B; } \\
\text { AHNAK; S100A10; } \\
\text { Annexin II }\end{array}$ & {$[50,100-107]$} \\
\hline & $\begin{array}{l}\text { Caveolae- } \\
\text { mediated } \\
\text { endocytic repair }\end{array}$ & $\begin{array}{l}\text { Mechanical } \\
\text { wounding }\end{array}$ & $\begin{array}{l}\text { ASM }^{2} \text {; Caveolin-3; } \\
\text { annexin I }\end{array}$ & [108-113] \\
\hline \multirow[t]{2}{*}{$\begin{array}{l}\text { Epithelial } \\
\text { cells }\end{array}$} & $\begin{array}{l}\text { Caveolae- } \\
\text { mediated } \\
\text { endocytosis }\end{array}$ & $\mathrm{PFTs}^{1}$ & $\begin{array}{l}\text { ASM; Caveolin-3; } \\
\text { annexin I }\end{array}$ & {$[45,108,110]$} \\
\hline & $\begin{array}{l}\text { ESCRT- } \\
\text { mediated } \\
\text { shedding }\end{array}$ & PFTs & $\begin{array}{l}\text { ALG-2; ESCRT-III; } \\
\text { ALIX; Vps4 }\end{array}$ & {$[74,114]$} \\
\hline
\end{tabular}

PFTs: Pore-forming toxins; ASM: Acid Sphingomyelinase

Table 1. Wound healing mechanisms according to cell-type. 


\begin{tabular}{|c|c|c|c|c|c|}
\hline & 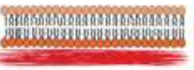 & 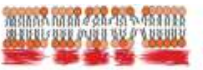 & 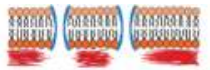 & 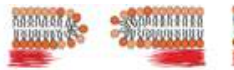 & oseming \\
\hline Wound type & $\begin{array}{c}\text { Unwounded } \\
\text { plasma membrane }\end{array}$ & $\begin{array}{l}\text { Very small wounds } \\
\text { (electroponation, } \\
\text { osmotic shock) }\end{array}$ & PFTs & $\begin{array}{l}\text { Small } \\
\text { mechanical wounds }\end{array}$ & Large mechanical wounds \\
\hline $\begin{array}{l}\text { Effect of wound on: } \\
\text { Calcium entry }\end{array}$ & . & Small uniform entry & $\begin{array}{l}\text { Highly localized } \\
\text { to pore site }\end{array}$ & $\begin{array}{l}\text { Localized and restricted } \\
\text { at wound site }\end{array}$ & $\begin{array}{l}\text { Localized and restricted } \\
\text { at wound site }\end{array}$ \\
\hline Apparent Membrane Tension & - & None to small increase & None & Small increase & Large increase \\
\hline In-plone membrane tension & - & None & None & Small increase & Large increase \\
\hline MCAs & - & Small uniform & $\begin{array}{l}\text { Disruptions localized } \\
\text { at pore-sites }\end{array}$ & $\begin{array}{l}\text { Disruptions localized } \\
\text { at wound-sites }\end{array}$ & $\begin{array}{l}\text { Disruptions over large } \\
\text { areas and wound-site }\end{array}$ \\
\hline Role of exocytosis & - & $-\uparrow$ membrane area & $\begin{array}{l}\text { - } \uparrow \text { membrane area } \\
\text {-ASM delivery } \\
\text { to outer leaflet }\end{array}$ & $\begin{array}{c}-\uparrow \text { membrane area } \\
\text {-ASM delivery } \\
\text { to outer leaflet }\end{array}$ & $\begin{array}{l}-\uparrow \text { membrane area } \\
\text {-ASM delivery } \\
\text { to outer leaflet }\end{array}$ \\
\hline $\begin{array}{l}\text { Possible wound } \\
\text { healing mechanism(s) }\end{array}$ & - & $\begin{array}{l}\text { Spontaneous resealing } \\
\text {-Caveolae flattening }\end{array}$ & $\begin{array}{c}\text {-Endocytic degradation } \\
\text {-Ectocytosis }\end{array}$ & $\begin{array}{l}\text {-Exocytic repair } \\
\text {-Facilitated repair } \\
\text {-Endocytic repair } \\
\text { (Cartulac-mediated repuir) } \\
\text {-Blebbing and } \\
\text { membrane shedding } \\
\text { (ESCRT, Annexin II:S100A10, etc) }\end{array}$ & $\begin{array}{l}\text { "Membrane patch" } \\
\text {-Endocytic repair } \\
\text { (Certolac-mediated npuir) }\end{array}$ \\
\hline
\end{tabular}

Figure 2. Schematic (top) depicts lateral sections of the plasma membrane before and after different types of wounding (individual phospholipids represented as orange and beige heads with hairpin-like tails; cortical actin network represented as red lines; toxic pores represented in blue). Table (bottom) lists changes to wound-type-dependent factors of $\mathrm{Ca}^{2+}$ influx and tension, role of exocytosis and possible wound healing mechanisms upon different types of wounding. MCAs: membrane-to-cortex attachments; PFTs: pore-forming toxins.

\subsection{Large wounds: exocytic repair, membrane patches and endocytic repair}

\subsubsection{Oocytes}

Oocytes of Xenopus laevis and sea urchins are large, easily accessible and manipulable cells. While their size and lack of adhesive and cell-cell contact-derived tension distinguish them from mammalian somatic cells, these characteristics also provide a simpler platform which helped to elaborate the first models of single-cell wound healing. Oocytes have been observed to recover form very large mechanical disruptions of both the plasma membrane and cytoskeleton $\left(>1000 \mu \mathrm{m}^{2}\right)$ [75].

\subsubsection{1. "Membrane patch"-mediated resealing}

In addition to providing essential amino acids and other nutrients for oocyte development, yolk platelets also act as vesicle reservoirs upon plasma membrane injury of oocytes in a variety of species [22, 75]. Upon wounding, there is a rapid influx of $\mathrm{Ca}^{2+}$ from the extracellular milieu to the intracellular space, which favors rapid homotypic fusions of yolk granules [75]. These homotypic vesicular fusogenic events lead to the formation of a large "membrane patch" that eventually covers the gap present at the wound site [75-77]. It is perhaps best to think of the "membrane patch" model of wound healing as a somewhat oocyte-specific process. Indeed, 
this model relies almost entirely on homotypic fusions [75], and yolk granules offer a pool of readily available vesicle reserves that is incomparable with those available to somatic cells [78]. Also, while the "membrane patch" model of single-cell repair has also initially been proposed for the repair of large wounds in somatic cells $[79,80]$, it now appears that large somatic cell membrane disruptions are directly removed by endocytosis, which heavily relies on exocytosis and heterotypic fusion events (reviewed in [35, 81]; see Section 4.1.3.2). Whether these apparent differences are an intrinsic property of oocytes, a direct consequence of the wound size involved, larger wounds exposing larger areas of the intracellular space to $\mathrm{Ca}^{2+}$, or of the higher density of available vesicles in oocytes, remains open for interpretation.

While the mechanism behind membrane patch formation is sufficient to block unregulated exchanges between extra- and intracellular spaces, it does not technically reseal the membrane, or restore membrane continuity or normal plasma membrane composition and shape. The way this resealing is achieved is still somewhat unclear and is the subject of two alternate but compatible models. The first states that heterotypic fusion events between intracellular vesicles, the membrane patch and the borders of the wounded plasma membrane first restore membrane continuity, after which contraction of an actomyosin ring restores normal plasma membrane composition and shape ([82]; see Section 4.1.1.2). The so-called "vertex fusion" model relies on the same heterotypic fusion events but states that multiple fusion pores would form around the periphery of the wounded region. Expansion of these fusion pores may cause shedding of a membrane fragment containing both wound residual portions of the patch vesicle, in a mechanism reminiscent of the one observed for yeast vacuoles ([83, 84]; reviewed in [81]).

\subsubsection{Actomyosin contractile ring}

As previously discussed, disruptions of the plasma membrane may be accompanied by, as well as induce direct and indirect cytoskeletal disruptions. Restoration of the local cytoskeleton is primarily driven by the contraction of a purse-string structure primarily assembled from Factin and myosin II [82]. This actomyosin ring is anchored to the plasma membrane at frequent points along its border [82], and its closure has been shown to restore normal membrane composition and shape [82].

Formation of the actomyosin array is controlled by the $\mathrm{Ca}^{2+}$-dependent recruitment and activation of Rho family GTPase proteins [85]. In Xenopus oocytes, activated Rho GTPases Ras homolog family member A (RhoA) and cell division control protein 42 homolog (Cdc42) localize to exclusive, concentric zones around the wound [86, 87]. These GTPases influence the activities of, among many other downstream targets, myosin light-chain kinase (MLCK) and myosin phosphatase [88, 89]. Through the above effectors, RhoA indirectly regulate the phosphorylation levels of myosin II light chains, mediating the assembly and contraction of the actomyosin ring (reviewed in [85]). As for Cdc42, its interactions with neural WiskottAldrich syndrome protein (N-WASP) and actin-related protein 2/3 (Arp2/3) [90-92] induce construction of highly dynamic, branched F-actin networks [86]. Binding of Arp2/3 with the $\mathrm{C}$ terminus of N-WASP, which is activated by Cdc42, stimulates Arp2/3's actin nucleation activity [91], accelerating production of actin networks critically involved in actomyosin ring 
assembly. The formation of contractile arrays has been demonstrated to also be regulated by an underlying "signaling treadmill" [93] in which gradients of Rho GTPase activities influence F-actin turnover. RhoA is preferentially activated and maintains its zone of high activity at the leading edge of the wound [93], while active Cdc42 encircles the inner RhoA zone [86]. The processes leading to the establishment of these concentric zones is still somewhat unclear, but a recent study by Vaughan et al. [94] has led to some interesting insights. They observed that wounding induced the formation of micrometer-scale $\mathrm{PIP}_{2-}$, phosphatidylinositol 3,4,5trisphosphate $\left(\mathrm{PIP}_{3}\right)$ - and phosphatidylserine (PS)-, phosphatidic acid (PA)- and diacylglycerol (DAG)-enriched domains. This is of particular interest as PS moved to a zone closest to the wound edge, near to an area of high RhoA activity, whereas $\mathrm{PIP}_{2}$ and $\mathrm{PIP}_{3}$ were observed to be associated with the so-called Cdc42 zone. As for DAG and PA, both of them were shown to immediately segregate in a zone overlapping that of which of RhoA and Cdc42 activity. Since DAG is known to be able to recruit PKC $\beta$ and PKC $\eta$ [95], the authors suggested that generation of DAG at the wound site could therefore act as an upstream signal for the regulation of RhoA and Cdc42. Whether a similar signal cascade exist for somatic cells is still unclear, but celllifting experiments done of primary epithelial cells induced phospholipase D (PLD) activation was transient, consistent with a possible role in membrane repair and PLD inhibitors inhibited membrane resealing upon laser injury [96].

Whether such a contractile ring can form in the smaller wounds associated with somatic cells is unclear, but the formation of strikingly similar concentric zones of Rho1, Cdc42 and Rac have been shown to form in Drosophila syncytial embryos following plasma membrane wounding (reviewed in [97]).

\subsubsection{Neuronal cells and fibroblasts: insights into exocytic repair}

Neuronal cells have markedly polarized membranes, with extreme distances between axons and the cell soma. The elongated morphology of axons make them particularly susceptible to shear stress injury and offering a challenge to vesicle trafficking. Fibroblasts, on the other hand, offer a relatively simpler platform for the study of single-cell wound healing.

While the repair of oocytes relies on homotypic fusion of abundant yolk granules (see Section 4.1.1.1), repair of mammalian cells has long been observed to depend on the $\mathrm{Ca}^{2+}$-dependent exocytosis of intracellular vesicles [98]. Conventional lysosomes are not only the major vesicles responsible for $\mathrm{Ca}^{2+}$-dependent exocytosis in non-neuronal and non-secretory cells [99], but also occupy a central role in the exocytic [100] and endocytic models of single-cell repair (see Section 4.1.3.2). The lysosomes involved in plasmalemma repair can be defined as lysosomalassociated membrane protein 1 (LAMP-1)-positive [100], acid sphingomyelinase (ASM)containing intracellular vesicles [101].

Exocytosis-mediated repair attracted considerable interest when Steinhardt et al. [98] specified the mechanistic similarities with $\mathrm{Ca}^{2+}$-triggered synaptic exocytosis, both of which are dependent on $\mathrm{Ca}^{2+}[102,103]$ and actin cytoskeleton dynamics [104-106]. $\mathrm{Ca}^{2+}$-triggered synaptic exocytosis involves the interaction of synaptotagmin I, a C2 domains-containing protein present in exocytic vesicles and the soluble N-ethylmaleimide-sensitive factor (NSF) 
attachment protein receptor (SNARE) complexes of the synaptic membrane (reviewed in [107]). Interestingly, neurotransmission inhibitors botulinum neurotoxin A and B also negatively affected or completely blocked membrane healing in sea urchin embryos and Swiss 3T3 fibroblasts [98]. Similarly, treatment with an antibody targeting the active synaptotagmin IC2A domain was observed to prevent membrane resealing of squid and crayfish giant axons [108], 3 T3 fibroblasts [100] and rat PC12 cells [109]. In contrast to the neuron-specific synaptotagmin I [110], synaptotagmin VII is ubiquitously expressed and has been found to also influence exocytic membrane repair of other cell types such as sea urchin embryos [98, 103], Chinese hamster ovary cells [100], Swiss 3T3 fibroblasts [98, 100, 111], mouse embryonic fibroblasts [112] and epithelial cells [113-115]. Indeed, embryonic fibroblasts of synaptotagmin VIIdeficient mice were observed to have defects in lysosome exocytosis and wound resealing [112]. The mechanism involves the $\mathrm{Ca}^{2+}$-dependent activation and recruitment of synaptotagmin VIII-positive vesicles [111], which are then transported to the wound site via microtubuledependent trafficking [116]. Once at the plasma membrane, lysosome-bound synaptotagmin VII interacts with the SNARE formed by vesicle-associated membrane protein 7 (VAMP-7), syntaxin-4 and synaptosomal-associated proteins (SNAPs), such as SNAP-23, which leads to heterologous fusion of the lysosome with the plasma membrane [115].

As opposed to the "membrane-patch" model that relies on predominantly homotypic fusions, the exocytic model of single-cell repair assumes the predominance of heterotypic fusion events with the plasma membrane. Indeed, early microneedle-wounding experiments clearly showed a punctate distribution of lysosomal marker LAMP-1 around the wound site [100]. These heterotypic fusion events were initially thought to promote resealing by increasing plasma membrane surface area [100,117], thereby lowering in-plane membrane tension (see Section 3.1), which could theoretically favor spontaneous resealing events between the two wound edges of with nearby vesicles [118]. Indeed, inhibiting the lowering of in-plane membrane tension via actin stabilization, or by inhibiting exocytosis via neurotoxins A and B $([51,118]$ inhibits successful cell repair but is rescued by artificially reducing in-plane tension via the addition of surface active Pluronic F68 NF [51]).

As previously stated, the in-plane tension lowering effect of exocytosis indubitably has been shown to be crucial for plasma membrane repair of a variety of wounds (reviewed in [35, 119]), several lines of evidence have shown that they are not the last process in the resealing of plasma membranes. Indeed, aside from the notable exceptions of facilitated membrane repair that involves recruitment of additional vesicles originating from the transgolgi network (TGN) [120], there is little to no evidence that large micrometer size wounds are repaired via purely exocytic means. Rather, it seems that exocytosis acts as a preliminary step of other wound-healing process (see Section 4.1.3.2). In fact, there is debate as to whether conclusions made in earlier studies of exocytosis were misinterpretations of endocytic vesicles as an exocytic patch or vesicles, due to the studies being performed in the absence of extracellular endocytic tracers [121]. Similarly, there is also considerable evidence that the synaptotagmin VII/SNARE system may not be the only, or even the main, fusogenic system that mediates $\mathrm{Ca}^{2+}$-dependent exocytosis following injury, at least in cells that are under constant mechanical assault such as muscle fibers and muscle cells (see Section 4.1.3). 


\subsubsection{Muscle cells}

\subsubsection{Dysferlin-mediated exocytosis}

Muscle fibers are highly mechanically active and endure constant mechanical stresses from movement and exercise, and therefore are prone to stress-related injury. Indeed, their tubular morphology further facilitates the generation of shear stress along the long axis upon eccentric contraction, in which the muscle fiber lengthens while its constituent sarcomeres contract [122]. T-tubules are invaginations of the sarcolemma that run perpendicular to the overall muscle fiber's long axis. These invaginations penetrate deep into the muscle fiber and mediate depolarization of membrane potential required for proper muscle contraction via excitationcontraction coupling. High levels of normal stress exerted on T-tubules upon eccentric contraction may rupture them, thereby severely disrupting the local sarcolemma [123, 124]. As such, muscle cells, especially muscle fibers, evolved potent single-cell repair mechanisms to cope with the constant duress under which they find themselves. For this reason, muscle cells and muscle fibers were instrumental in the study of mechanisms responsible for mammalian somatic single-cell repair.

Dysferlin was initially identified as genetic causes of limb-girdle muscular dystrophy 2B (LGMD2B) [125] and Miyoshi myopathy [126], and dysferlin has since been shown to be ubiquitously expressed with particularly high levels in skeletal muscle, heart and kidney [127]. Its prominence in muscle membrane repair was experimentally demonstrated when dysferlinnull mice were observed to develop progressive limb-girdle muscular dystrophy $2 \mathrm{~B}$ due to defects in $\mathrm{Ca}^{2+}$-dependent sarcolemma resealing [128]. Dysferlin is a member of the C2domain-containing ferlin family, which are known regulators of $\mathrm{Ca}^{2+}$-dependent vesicle fusion for auditory neurotransmission [34, 129, 130] and are believe to be functionally similar to synaptotagmin I [131]. Dysferlin's localization at the sarcolemma [132] has led to its research in the context of sarcolemma repair. Indeed, it appears that in muscle cells, dysferlin is at the center of $\mathrm{Ca}^{2+}$-dependent exocytosis following injury, after which intracellular membranes are delivered to the plasma membrane, and ASM released to the outer leaflet [133].

Molecular events involved in dysferlin-mediated exocytosis are a lot more complex than the one involved in synaptotagmin VII/SNAREs-mediated fusions. Indeed, dysferlin has been shown to bind to or be associated with a relatively high number of proteins including MG53 [134, 135], caveolin-3 [134], annexin I [136] and many others (reviewed in [137]). However, a study of human myoblasts by Lek et al. [50] led to the discovery that a calpain-cleaved product of dysferlin played a direct role in the sarcolemma's exocytic repair mechanism. Briefly, calpains activated by injury-induced $\mathrm{Ca}^{2+}$ influx cleave dysferlin, which releases its $\mathrm{C}$-term fragment mini-dysferlinC72 [50, 138, 139]. Following vesicle packaging, mini-dysferlinC72containing cytoplasmic vesicles are then transported to the wound site. Once localized, minidysferlinC72 interacts with MG53 compartments to form an array, which has been proposed to promote repair by way of wound stabilization (see Section 3.2), as well as promote heterotypic fusion between intracellular vesicles [140] and the sarcolemma [50, 138, 139].

Interestingly, dysferlin has also been shown to associate with AHNAK and may be related to enlargeosome exocytosis. Enlargeosomes are small, AHNAK-positive vesicles resistant to 
nonionic detergents that undergo endocytosis via a nonacidic route and are supposedly distinct form other conventional vesicular compartments [141]. AHNAK [142] is a very large $(\approx 700 \mathrm{KDa})$ protein involved in a variety of distinct functions and pathologies (reviewed in [143]). The exact nature and contribution of enlargeosomes to dysferlin-mediated repair is still somewhat ill defined and may vary according to wound severity and cell type. Indeed, their regulated exocytoses have been suggested to add significant amount of membrane components to the injured plasmalemma in neuronal cells [144] and may therefore be involved in either endocytic (see Section 4.1.3.2) or shedding-mediated repair (see Section 4.2.3) [145]. Dysferlin may also modulate plasma membrane repair via its interaction with the AHNAK/ S10010A10/Annexin II complex, which is a known organizer of the actin cytoskeleton and plasma membrane architecture [146].

Hence, contrary to oocytes, dysferlin-mediated exocytosis does not exclusively lead to the formation of a "patch," which also results in diminished in-plane membrane tension and ASM release to the outer leaflet.

\subsubsection{Caveolae-mediated endocytic repair of mechanical wounds}

Exocytosis is insufficient to fully explain the repair of membrane disruptions as lesions from pore-forming proteins are readily removed from the plasma membrane (see Section 4.2.1), which is not explainable by exocytosis alone. Also, the repair of SLO and mechanical lesions has been shown not to depend on exocytosis per se, but on the injury-induced release of ASM. Indeed, ASM deficiency, as seen in Niemann-Pick disease (NPD) types A and B [147], is capable of $\mathrm{Ca}^{2+}$-dependent exocytosis but have severely limited $\mathrm{Ca}^{2+}$-dependent endocytosis and shows signs of defective plasma membrane repair, both of which can be rescued by exogenously provided ASM [101, 148]. Similarly, inhibition of ASM by desipramine inhibited both endocytosis and normal plasma membrane repair [101]. This injury-induced endocytosis had previously been described and suggested to be involved in the endocytic degradation of SLO pores and of mechanical disruptions [149]. The same study identified the endosomes involved to be $\mathrm{Ca}^{2+}$ - and cholesterol dependent [149], but did not offer any mechanistic insight into their formation. As previously stated, caveolae are lipid-raft-rich whose formation is dependent on cholesterol, PIP $_{2}$ and PS (see Section 3.1), and are known to be facilitated by the transient formation of ceramide on lipid rafts [150,151]. Once released to extracellular fluid, ASM cleaves the phosphorylcholine heads of sphingomyelin leaflets on the membrane surface to generate ceramide sphingolipids [152]. The resulting ceramide-enriched domains of the phospholipid bilayer are more prone to membrane invaginations due to them encompassing a smaller molecular area relative to other membrane lipids [152], promoting caveolae's endocytic function [153-155]. Similarly, caveolin-3 deficiency causes muscle degeneration in mice [134], which mirrors the limb-girdle muscular dystrophy 1C (LGMD1C) phenotype in humans [156]. As such, exocytosis of lysosomes and dysferlin vesicles after plasma membrane injury may not heal the membrane directly, but rather facilitate membrane resealing by encouraging caveolae formation. Indeed, upon heterotypic fusion with the membrane, ASM is released to the outer surface of the membrane, which potentiates the formation of ceramide-rich platforms that have been shown to trigger invagination of the plasmalemma [157] and formation of 
caveolae-derived endosomes (reviewed [158]). Indeed, transmission electron microscopy (TEM) has shown that caveolae were found to be concentrated next to mechanical disruptions of muscle cells [153] and assemble into a single, large merged caveolae-like structure around the large wounds generated in primary muscle fibers [153]. As Corrotte et al. correctly pointed out, these very large endocytic vesicles and invaginations may have initially been identified as related to the exocytic "patch" that was initially proposed to cover and eventually heal wounds in muscle cells (see Section 4.1.3.1). Alternatively, Corrotte et al. [153] proposed an endocytic-mediated model of plasma membrane repair. Briefly, large caveolae-like invaginations are formed as a consequence of a combination of the lower in-plane tension provided by the exocytosis of lysosomes, dysferlin-positive vesicles, changes in plasma membrane shape that follows release of ASM, and the presence of proteins such as dysferlin and caveolins. The growth and eventual fusion of those caveolae-like invaginations provides a "constriction force" that promotes plasmalemma resealing [153].

Endocytosis leads to a decrease in total plasma membrane surface area, increasing in-plane membrane tension and providing the force necessary for the mechanical wound removal. It is, however, important to consider that exocytosis of ASM lysosomes always precedes caveolae-mediated endocytosis. The corresponding in-plane membrane tension increases likely readjusts overall apparent membrane tension back to the cell's pre-injury levels, as typeI alveolar epithelial cells are known to remediate to hypertonic shock by increased caveolaemediated endocytosis [159]. In fact, endocytic repair seems not to be as muscle specific as it was once thought since alveolar cell repair has been suggested to be linked to MG53 and caveolin-1 [160, 161].

\subsection{Small wounds: ectocytic repair, blebbing and membrane shedding}

\subsubsection{Ectocytic repair of pore-forming toxins and blebbing of small mechanical wounds}

As previously stated, caveolae-mediated endocytosis was shown to mediate the repair of membrane disruptions created by pore-forming toxins [45]. Indeed, SLO was directly visualized entering cells within caveolar vesicles [153]. Post-internalization, the pore has been shown to be ubiquitinated and eventually degraded by lysosomal hydrolysis [45].

While endocytic repair of SLO pores is now a widely accepted mechanism, it still raises some questions as SLO pores were shown to be successfully removed from the neurites of SH-SY5Y neuroblastoma cells [162]. SH-SY5Y cells are devoid of lysosomes and hence cannot undergo caveolae-mediated endocytosis.

As discussed in Section 3.3.1, $\mathrm{Ca}^{2+}$ entry can lead to local actin depolymerization, which in turn leads to a diminution of apparent membrane tension, and the formation of membrane blebs [163]. Indeed, bleb formation seems to principally depend on osmotic pressure and MCAs, the contribution of in-plane tension being minimal [164, 165]. Formation of membrane blebs can be initiated by laser ablation of the cortex cytoskeletal structures [163]. This also explains why formation of membrane blebs is inhibited by drugs that leads to depolymerization [166] or stabilization [167] of the actin cytoskeleton. 
SLO pores cause localized $\mathrm{Ca}^{2+}$ entry and actin depolymerization without creating large plasma membrane tears-related increases in membrane tension (see Section 3.3.1). As such, it is not surprising that small blebs may be involved in the removal of SLO pores [168]. It should be noted that the same observations strongly suggest that SLO pore insertion, pore assembly, pore clustering and even bleb formation may be $\mathrm{Ca}^{2+}$-independent [168]. This is controversial, however, as it would imply that SLO pore insertion could possibly displace proteins responsible of the interaction of the plasmalemma with the cytoskeleton. This also poses a problem, as other teams have shown a $\mathrm{Ca}^{2+}[169]$ and actin disruption [162] dependence for the survival of SLO-treated cells [169], and for the shedding of SLO-laden microvesicles [162]. In this alternate model [162], pore disruption of the membrane elevates local $\mathrm{Ca}^{2+}$ concentration which in turn activates annexins and calpains. Calpains then disrupt the underlying actin cytoskeleton, thereby facilitating bleb formation [170] and shedding of SLO vesicles.

\subsubsection{ESCRT-mediated shedding of small disruptions}

The endosomal sorting complex required for transport (ESCRT) complexes are factors of the lysosomal pathway during protein processing and are involved in various membrane remodeling events such as lysosomal targeting of ubiquitinated proteins and multivesicular body biogenesis, as well as cytokinetic abscission ([171]; reviewed by Olmos and Carlton [172]). There are five currently known ESCRT complexes: ESCRT-0, ESCRT-I, ESCRT-II, ESCRT-III and ESCRT-IV. Of these, ESCRT-III has since been found to modulate much of the membrane remodeling processes, while ESCRT-0, ESCRT-I and ESCRT-II facilitate its targeting to specific cellular compartments, ESCRT-IV orchestrating the disassembly of the ESCRT-III complex for subunit recycling (reviewed in [173]). An additional function of ESCRT-III in plasma membrane repair was proposed in a recent study, which suggested that ESCRT-III is involved in the pinching out or shedding of wounded membranes in HeLa cells [74]. Indeed, injuryinduced $\mathrm{Ca}^{2+}$ increase results in $\mathrm{Ca}^{2+}$ binding of apoptosis-linked gene-2 (ALG-2) around the site of disruption. Active ALG-2 initiates ESCRT machinery assembly by facilitating the accumulation of ALG-2-interacting protein X (ALIX) near the wound site, after which ALG-2 and ALIX recruit ESCRT-III and vacuolar protein sorting-associated protein 4 (Vps4) to the injured plasma membrane [74, 174]. These subunits form a complex, which cleave and shed the wound from the plasma membrane to extracellular space [174]. ESCRT-mediated shedding leads to a decrease in total plasma membrane surface area, increasing in-plane membrane tension.

\section{Conclusion}

Injury-induced disruptions to the plasma membrane's shape and composition directly affect the cell's tensegrity. The different active membrane repair mechanisms that have been discussed in this chapter are perhaps best seen as a single interconnected pathway, in which the type and size of the wound determine the extent and severity of factors such as tension change and $\mathrm{Ca}^{2+}$ entry. These factors in turn dictate the healing mechanisms being used (Table 1 and 
Figure 2). Mechanical lesions lead to high, localized levels of membrane integrity loss, tension change and $\mathrm{Ca}^{2+}$ influx. These physical tears of the plasma membrane are often repaired by targeted exocytosis and endocytosis. Contrastingly, smaller injuries such as those generated by electroporation and osmotic shock induce low levels of membrane disruption, tension change and $\mathrm{Ca}^{2+}$ influx across large membrane areas. These in turn facilitate processes such as cytoskeletal remodeling or caveolae flattening. Conversely, membranes disrupted by toxic pores do not lead to substantial increase in plane tension. As such, they can either be rapidly shed or degraded following caveolae-mediated endocytosis. Furthermore, it appears that the wound-healing mechanisms prevalent in a given cell-type fall not only in accordance with the prevalence of specific injury types (i.e., PFTs vs. tears vs. ablations), but also according to cell type-specific differences in cell tensegrity and polarity (e.g., muscle cells vs. epithelial cells).

Similar to the plasma membrane and cytoskeletal elements interact to create tensegrity in the single-cell scale, adhesive forces of single cells and the extracellular matrix (ECM) provide structural stiffness to tissues [1]. Considering the above, it should be no surprise that successful single-cell repair influences the success of tissue repair. Indeed, contrary to tissue repair, singlecell repair is largely a binary event: it either takes place allowing the cell's survival, or not, leading to lysis or apoptotic removal. While relevant to wound healing at the tissue-level, these events have little to no relevance for single-cell wound healing outside of the modification of the environment of other injured cells in the surrounding area (asymmetric binding, change in $\mathrm{ROS}, \mathrm{Ca}^{2+}$ concentration, etc.). Conversely, it seems that successful repair in one cell may lead to an increased repair potential in surrounding cells $[175,176]$. This "potentiated" repair has been shown to involve purinergic and nitric oxide (NO)/PKG-signaling pathways [175, 176]. Similarly, repeated insults to a cell's structural and membrane integrity presumably affect a cell's ability to undergo subsequent membrane resealing and cytoskeletal repair, which would be reflected in its long-term viability in a given tissue. Indeed, the prominent view of the origin of the phenotypes associated with muscular dystrophies point toward a heighted susceptibly to repeated mechanical wounding, leading in turn in a higher rate of single-cell repair failure (reviewed in [177, 178]).

Another parallel between single-cell and tissue wound-healing mechanisms is their reliance on contractile arrays. This similarity has been confirmed in multicellular models such as Xenopus embryos [179], Caco-2 intestinal epithelial monolayers [180] and Madin-Darby canine kidney (MDCK) epithelial monolayers [181].

Wound closure in epithelial sheets has been demonstrated to be driven by the coupling of actomyosin contraction and collective cell migration [182-185]. The relative contribution of each mechanism in overall re-epithelialization depends on numerous biomechanical factors, including wound geometry [182-184], wound size [182, 186], tissue stiffness [186] and ECM composition [182]. In particular, wounds of cultured bovine corneal endothelial cell monolayers in ECM-deprived conditions were observed to reseal predominantly through actomyosin activity [182]. This is intriguing since cytoskeletal dynamics greatly influence single-cell wound-healing processes (see Section 3.3) and exhibits the ECM and cytoskeleton's analogous relationship across biological scales in the context of wound healing. These observations 
suggest that the importance of tensegrity components in wound repair are conserved across single-cell and multicellular models.

Considering the single cell's tensegral context in future wound-healing study will help further characterize an increasingly complex unified pathway theory of plasma membrane repair.

\section{Author details}

Eric Boucher, Tatsuya Kato and Craig A. Mandato*

*Address all correspondence to: craig.mandato@mcgill.ca

Department of Anatomy and Cell Biology, Faculty of Medicine, McGill University, Montreal, Quebec, Canada

\section{References}

[1] Ingber, D.E., N. Wang, and D. Stamenovic, Tensegrity, cellular biophysics, and the mechanics of living systems. Rep Prog Phys, 2014. 77(4): p. 046603.

[2] Fuller, R.B., Tensegrity. Portfolio Art News Annu, 1961. 4: pp. 112-27, 144, 148.

[3] Wang, N., et al., Mechanical behavior in living cells consistent with the tensegrity model. Proc Natl Acad Sci U S A, 2001. 98(14): pp. 7765-70.

[4] Mendez, M.G., D. Restle, and P.A. Janmey, Vimentin enhances cell elastic behavior and protects against compressive stress. Biophys J, 2014. 107(2): pp. 314-23.

[5] Chen, C., et al., Effects of vimentin disruption on the mechanoresponses of articular chondrocyte. Biochem Biophys Res Commun, 2016. 469(1): pp. 132-7.

[6] Diz-Munoz, A., D.A. Fletcher, and O.D. Weiner, Use the force: membrane tension as an organizer of cell shape and motility. Trends Cell Biol, 2013. 23(2): pp. 47-53.

[7] Xue, F., et al., Effect of membrane stiffness and cytoskeletal element density on mechanical stimuli within cells: an analysis of the consequences of ageing in cells. Comput Methods Biomech Biomed Engin, 2015. 18(5): pp. 468-76.

[8] Knoll, R., A role for membrane shape and information processing in cardiac physiology. Pflugers Arch, 2015. 467(1): pp. 167-73.

[9] Chatterjee, S., et al., Shear stress-related mechanosignaling with lung ischemia: lessons from basic research can inform lung transplantation. Am J Physiol Lung Cell Mol Physiol, 2014. 307(9): pp. L668-80. 
[10] Vuckovic, A., et al., Alveolarization genes modulated by fetal tracheal occlusion in the rabbit model for congenital diaphragmatic hernia: a randomized study. PLoS One, 2013. 8(7): p. e69210.

[11] Myers, K.A., et al., Hydrostatic pressure sensation in cells: integration into the tensegrity model. Biochem Cell Biol, 2007. 85(5): pp. 543-51.

[12] Parsegian, V.A., R.P. Rand, and D. Gingell, Lessons for the study of membrane fusion from membrane interactions in phospholipid systems. Ciba Found Symp, 1984. 103: pp. 9-27.

[13] Zhelev, D.V. and D. Needham, Tension-stabilized pores in giant vesicles: determination of pore size and pore line tension. Biochim Biophys Acta, 1993. 1147(1): pp. 89-104.

[14] Hoffman, J.F., On red blood cells, hemolysis and resealed ghosts. Adv Exp Med Biol, 1992. 326: pp. 1-15.

[15] Kay, J.G. and S. Grinstein, Sensing phosphatidylserine in cellular membranes. Sensors (Basel), 2011. 11(2): pp. 1744-55.

[16] Riske, K.A. and R. Dimova, Electro-deformation and poration of giant vesicles viewed with high temporal resolution. Biophys J, 2005. 88(2): pp. 1143-55.

[17] Gozen, I. and P. Dommersnes, Pore dynamics in lipid membranes. European Physical Journal-Special Topics, 2014. 223(9): pp. 1813-1829.

[18] Thompson, N.L. and D. Axelrod, Reduced lateral mobility of a fluorescent lipid probe in cholesterol-depleted erythrocyte membrane. Biochim Biophys Acta, 1980. 597(1): pp. 15565.

[19] Golan, D.E., et al., Lateral mobility of phospholipid and cholesterol in the human erythrocyte membrane: effects of protein-lipid interactions. Biochemistry, 1984. 23(2): pp. 332-9.

[20] Rand, R.P. and V.A. Parsegian, Physical force considerations in model and biological membranes. Can J Biochem Cell Biol, 1984. 62(8): pp. 752-9.

[21] Johnson, R.M. and D.H. Kirkwood, Loss of resealing ability in erythrocyte membranes. Effect of divalent cations and spectrin release. Biochim Biophys Acta, 1978. 509(1): pp. 58-66.

[22] McNeil, P.L., K. Miyake, and S.S. Vogel, The endomembrane requirement for cell surface repair. Proc Natl Acad Sci U S A, 2003. 100(8): pp. 4592-7.

[23] Tsai, P.S., et al., Syntaxin and VAMP association with lipid rafts depends on cholesterol depletion in capacitating sperm cells. Mol Membr Biol, 2007. 24(4): pp. 313-24.

[24] Zitranski, N., et al., The "acrosomal synapse": Subcellular organization by lipid rafts and scaffolding proteins exhibits high similarities in neurons and mammalian spermatozoa. Commun Integr Biol, 2010. 3(6): pp. 513-21.

[25] Correia, J., F. Michelangeli, and S. Publicover, Regulation and roles of Ca2+ stores in human sperm. Reproduction, 2015. 150(2): pp. R65-76. 
[26] Chander, A., et al., Annexin A7 trafficking to alveolar type II cell surface: possible roles for protein insertion into membranes and lamellar body secretion. Biochim Biophys Acta, 2013. 1833(5): pp. 1244-55.

[27] Ichimura, H., et al., Lung surfactant secretion by interalveolar Ca2+ signaling. Am J Physiol Lung Cell Mol Physiol, 2006. 291(4): pp. L596-601.

[28] Miklavc, P., et al., Ca2+-dependent actin coating of lamellar bodies after exocytotic fusion: a prerequisite for content release or kiss-and-run. Ann N Y Acad Sci, 2009. 1152: pp. 43-52.

[29] Cardenas, A.M. and F. Marengo, How the stimulus defines the dynamics of vesicle pool recruitment, fusion mode and vesicle recycling in neuroendocrine cells. J Neurochem, 2016. DOI: $10.1111 /$ jnc.13565.

[30] Chung, C. and J. Raingo, Vesicle dynamics: how synaptic proteins regulate different modes of neurotransmission. J Neurochem, 2013. 126(2): pp. 146-54.

[31] de Jong, A.P. and D. Fioravante, Translating neuronal activity at the synapse: presynaptic calcium sensors in short-term plasticity. Front Cell Neurosci, 2014. 8: p. 356.

[32] Shin, O.H., Exocytosis and synaptic vesicle function. Compr Physiol, 2014. 4(1): pp. 14975.

[33] Pangrsic, T., E. Reisinger, and T. Moser, Otoferlin: a multi-C2 domain protein essential for hearing. Trends Neurosci, 2012. 35(11): pp. 671-80.

[34] Beurg, M., et al., Control of exocytosis by synaptotagmins and otoferlin in auditory hair cells. J Neurosci, 2010. 30(40): pp. 13281-90.

[35] Boucher, E. and C.A. Mandato, Plasma membrane and cytoskeleton dynamics during singlecell wound healing. Biochim Biophys Acta, 2015. 1853(10 Pt A): pp. 2649-61.

[36] Yamada, E., The fine structure of the gall bladder epithelium of the mouse. J Biophys Biochem Cytol, 1955. 1(5): pp. 445-58.

[37] Dulhunty, A.F. and C. Franzini-Armstrong, The relative contributions of the folds and caveolae to the surface membrane of frog skeletal muscle fibres at different sarcomere lengths. J Physiol, 1975. 250(3): pp. 513-39.

[38] Kozera, L., E. White, and S. Calaghan, Caveolae act as membrane reserves which limit mechanosensitive $\mathrm{I}(\mathrm{Cl}$,swell) channel activation during swelling in the rat ventricular myocyte. PLoS One, 2009. 4(12): p. e8312.

[39] Calaghan, S., L. Kozera, and E. White, Compartmentalisation of cAMP-dependent signalling by caveolae in the adult cardiac myocyte. J Mol Cell Cardiol, 2008. 45(1): pp. 88-92.

[40] Sinha, B., et al., Cells respond to mechanical stress by rapid disassembly of caveolae. Cell, 2011. 144(3): pp. 402-13.

[41] Kovtun, O., et al., Cavin family proteins and the assembly of caveolae. J Cell Sci, 2015. 128(7): pp. 1269-78. 
[42] Shvets, E., A. Ludwig, and B.J. Nichols, News from the caves: update on the structure and function of caveolae. Curr Opin Cell Biol, 2014. 29: pp. 99-106.

[43] Hagiwara, Y., et al., Caveolin-3 deficiency causes muscle degeneration in mice. Hum Mol Genet, 2000. 9(20): pp. 3047-54.

[44] Wolfmeier, H., et al., Ca-dependent repair of pneumolysin pores: A new paradigm for host cellular defense against bacterial pore-forming toxins. Biochim Biophys Acta, 2015. 1853 (9): p. 2045-54.

[45] Corrotte, M., et al., Toxin pores endocytosed during plasma membrane repair traffic into the lumen of MVBs for degradation. Traffic, 2012. 13(3): pp. 483-94.

[46] Gerke, V. and S.E. Moss, Annexins: from structure to function. Physiol Rev, 2002. 82(2): pp. 331-71.

[47] Voges, D., et al., Three-dimensional structure of membrane-bound annexin $V$. A correlative electron microscopy-X-ray crystallography study. J Mol Biol, 1994. 238(2): pp. 199-213.

[48] Cezanne, L., et al., Organization and dynamics of the proteolipid complexes formed by annexin $V$ and lipids in planar supported lipid bilayers. Biochemistry, 1999. 38(9): pp. 2779-86.

[49] Bouter, A., et al., Annexin-A5 assembled into two-dimensional arrays promotes cell membrane repair. Nat Commun, 2011. 2: p. 270.

[50] Lek, A., et al., Calpains, cleaved mini-dysferlinC72, and L-type channels underpin calciumdependent muscle membrane repair. J Neurosci, 2013. 33(12): pp. 5085-94.

[51] Togo, T., et al., The mechanism of facilitated cell membrane resealing. J Cell Sci, 1999. 112 (Pt 5): pp. 719-31.

[52] Xie, X.Y. and J.N. Barrett, Membrane resealing in cultured rat septal neurons after neurite transection: evidence for enhancement by $\mathrm{Ca}(2+)$-triggered protease activity and cytoskeletal disassembly. J Neurosci, 1991. 11(10): pp. 3257-67.

[53] Miyake, K., et al., An actin barrier to resealing. J Cell Sci, 2001. 114(Pt 19): pp. 3487-94.

[54] Chen, X., et al., Single-site sonoporation disrupts actin cytoskeleton organization. J R Soc Interface, 2014. 11(95): p. 20140071.

[55] Deguchi, S. and M. Sato, Biomechanical properties of actin stress fibers of non-motile cells. Biorheology, 2009. 46(2): pp. 93-105.

[56] Sato, K., et al., Quantitative evaluation of threshold fiber strain that induces reorganization of cytoskeletal actin fiber structure in osteoblastic cells. J Biomech, 2005. 38(9): pp. 1895-901.

[57] Costa, K.D., W.J. Hucker, and F.C. Yin, Buckling of actin stress fibers: a new wrinkle in the cytoskeletal tapestry. Cell Motil Cytoskeleton, 2002. 52(4): pp. 266-74.

[58] Matsui, T.S., et al., Non-muscle myosin II induces disassembly of actin stress fibres independently of myosin light chain dephosphorylation. Interface Focus, 2011. 1(5): pp. 754-66. 
[59] Wu, T. and J.J. Feng, A biomechanical model for fluidization of cells under dynamic strain. Biophys J, 2015. 108(1): pp. 43-52.

[60] De La Cruz, E.M., J.L. Martiel, and L. Blanchoin, Mechanical heterogeneity favors fragmentation of strained actin filaments. Biophys J, 2015. 108(9): pp. 2270-81.

[61] Hayakawa, K., H. Tatsumi, and M. Sokabe, Mechano-sensing by actin filaments and focal adhesion proteins. Commun Integr Biol, 2012. 5(6): pp. 572-7.

[62] Hirata, H., et al., Non-channel mechanosensors working at focal adhesion-stress fiber complex. Pflugers Arch, 2015. 467(1): pp. 141-55.

[63] Hayakawa, K., H. Tatsumi, and M. Sokabe, Actin filaments function as a tension sensor by tension-dependent binding of cofilin to the filament. J Cell Biol, 2011. 195(5): pp. 721-7.

[64] Bernstein, B.W. and J.R. Bamburg, ADF/cofilin: a functional node in cell biology. Trends Cell Biol, 2010. 20(4): pp. 187-95.

[65] Orlova, A., et al., Actin-destabilizing factors disrupt filaments by means of a time reversal of polymerization. Proc Natl Acad Sci U S A, 2004. 101(51): pp. 17664-8.

[66] Martinac, B., Mechanosensitive ion channels: molecules of mechanotransduction. J Cell Sci, 2004. 117(Pt 12): pp. 2449-60.

[67] Muallem, S., et al., Actin filament disassembly is a sufficient final trigger for exocytosis in nonexcitable cells. J Cell Biol, 1995. 128(4): pp. 589-98.

[68] Biro, E.N. and S.Y. Venyaminov, Depolymerization of actin in concentrated solutions of divalent metal chlorides. Acta Biochim Biophys Acad Sci Hung, 1979. 14(1-2): pp. 31-42.

[69] Zechel, K., Stability differences of muscle F-actin in formamide in the presence of $\mathrm{Mg} 2+$ and Ca2+. Biochim Biophys Acta, 1983. 742(1): pp. 135-41.

[70] Ono, Y. and H. Sorimachi, Calpains: an elaborate proteolytic system. Biochim Biophys Acta, 2012. 1824(1): pp. 224-36.

[71] Nayal, A., D.J. Webb, and A.F. Horwitz, Talin: an emerging focal point of adhesion dynamics. Curr Opin Cell Biol, 2004. 16(1): pp. 94-8.

[72] Gasman, S., et al., Regulated exocytosis in neuroendocrine cells: a role for subplasmalemmal Cdc42/N-WASP-induced actin filaments. Mol Biol Cell, 2004. 15(2): pp. 520-31.

[73] Goodson, H.V., C. Valetti, and T.E. Kreis, Motors and membrane traffic. Curr Opin Cell Biol, 1997. 9(1): pp. 18-28.

[74] Jimenez, A.J., et al., ESCRT machinery is required for plasma membrane repair. Science, 2014. 343(6174): p. 1247136.

[75] Terasaki, M., K. Miyake, and P.L. McNeil, Large plasma membrane disruptions are rapidly resealed by Ca2+-dependent vesicle-vesicle fusion events. J Cell Biol, 1997. 139(1): pp. 63-74. 
[76] McNeil, P.L., et al., Patching plasma membrane disruptions with cytoplasmic membrane. J Cell Sci, 2000. 113 (Pt 11): pp. 1891-902.

[77] Abreu-Blanco, M.T., J.M. Verboon, and S.M. Parkhurst, Cell wound repair in Drosophila occurs through three distinct phases of membrane and cytoskeletal remodeling. J Cell Biol, 2011. 193(3): pp. 455-64.

[78] Karasaki, S., Studies on amphibian yolk 1. The ultrastructure of the yolk platelet. J Cell Biol, 1963. 18: pp. 135-51.

[79] Glover, L. and R.H. Brown, Jr., Dysferlin in membrane trafficking and patch repair. Traffic, 2007. 8(7): pp. 785-94.

[80] Han, R. and K.P. Campbell, Dysferlin and muscle membrane repair. Curr Opin Cell Biol, 2007. 19(4): pp. 409-16.

[81] Andrews, N.W., P.E. Almeida, and M. Corrotte, Damage control: cellular mechanisms of plasma membrane repair. Trends Cell Biol, 2014. 24(12): pp. 734-742.

[82] Mandato, C.A. and W.M. Bement, Contraction and polymerization cooperate to assemble and close actomyosin rings around Xenopus oocyte wounds. J Cell Biol, 2001. 154(4): pp. 785-97.

[83] Wang, L., et al., Vacuole fusion at a ring of vertex docking sites leaves membrane fragments within the organelle. Cell, 2002. 108(3): pp. 357-69.

[84] McNeil, P.L. and T. Kirchhausen, An emergency response team for membrane repair. Nat Rev Mol Cell Biol, 2005. 6(6): pp. 499-505.

[85] Darenfed, H. and C.A. Mandato, Wound-induced contractile ring: a model for cytokinesis. Biochem Cell Biol, 2005. 83(6): pp. 711-20.

[86] Benink, H.A. and W.M. Bement, Concentric zones of active RhoA and Cdc42 around single cell wounds. J Cell Biol, 2005. 168(3): pp. 429-39.

[87] Bement, W.M., H.A. Benink, and G. von Dassow, A microtubule-dependent zone of active RhoA during cleavage plane specification. J Cell Biol, 2005. 170(1): pp. 91-101.

[88] Kawano, Y., et al., Phosphorylation of myosin-binding subunit (MBS) of myosin phosphatase by Rho-kinase in vivo. J Cell Biol, 1999. 147(5): pp. 1023-38.

[89] Bishop, A.L. and A. Hall, Rho GTPases and their effector proteins. Biochem J, 2000. $348 \mathrm{Pt}$ 2: pp. 241-55.

[90] Egile, C., et al., Activation of the CDC42 effector N-WASP by the Shigella flexneri Ics A protein promotes actin nucleation by Arp2/3 complex and bacterial actin-based motility. J Cell Biol, 1999. 146(6): pp. 1319-32.

[91] Rohatgi, R., et al., The interaction between N-WASP and the Arp2/3 complex links Cdc42dependent signals to actin assembly. Cell, 1999. 97(2): pp. 221-231. 
[92] Taunton, J., et al., Actin-dependent propulsion of endosomes and lysosomes by recruitment of N-WASP. J Cell Biol, 2000. 148(3): pp. 519-30.

[93] Burkel, B.M., et al., A Rho GTPase signal treadmill backs a contractile array. Dev Cell, 2012. 23(2): pp. 384-96.

[94] Vaughan, E.M., et al., Lipid domain-dependent regulation of single-cell wound repair. Mol Biol Cell, 2014. 25(12): pp. 1867-76.

[95] Yu, H.Y. and W.M. Bement, Control of local actin assembly by membrane fusion-dependent compartment mixing. Nat Cell Biol, 2007. 9(2): pp. 149-59.

[96] Arun, S.N., et al., Cell wounding activates phospholipase D in primary mouse keratinocytes. J Lipid Res, 2013. 54(3): pp. 581-91.

[97] Abreu-Blanco, M.T., J.M. Verboon, and S.M. Parkhurst, Coordination of Rho family GTPase activities to orchestrate cytoskeleton responses during cell wound repair. Curr Biol, 2014. 24(2): pp. 144-55.

[98] Steinhardt, R.A., G. Bi, and J.M. Alderton, Cell membrane resealing by a vesicular mechanism similar to neurotransmitter release. Science, 1994. 263(5145): pp. 390-3.

[99] Jaiswal, J.K., N.W. Andrews, and S.M. Simon, Membrane proximal lysosomes are the major vesicles responsible for calcium-dependent exocytosis in nonsecretory cells. J Cell Biol, 2002. 159(4): pp. 625-35.

[100] Reddy, A., E.V. Caler, and N.W. Andrews, Plasma membrane repair is mediated by Ca(2+)regulated exocytosis of lysosomes. Cell, 2001. 106(2): pp. 157-69.

[101] Tam, C., et al., Exocytosis of acid sphingomyelinase by wounded cells promotes endocytosis and plasma membrane repair. J Cell Biol, 2010. 189(6): pp. 1027-38.

[102] Leitz, J. and E.T. Kavalali, Ca2+ Dependence of synaptic vesicle endocytosis. Neuroscientist, 2015. DOI: $10.1177 / 1073858415588265$.

[103] Bi, G.Q., J.M. Alderton, and R.A. Steinhardt, Calcium-regulated exocytosis is required for cell membrane resealing. J Cell Biol, 1995. 131(6 Pt 2): pp. 1747-58.

[104] Rust, M.B., ADF/cofilin: a crucial regulator of synapse physiology and behavior. Cell Mol Life Sci, 2015. 72(18): pp. 3521-9.

[105] Bi, G.Q., et al., Kinesin- and myosin-driven steps of vesicle recruitment for Ca2+-regulated exocytosis. J Cell Biol, 1997. 138(5): pp. 999-1008.

[106] McNeil, P.L., Repairing a torn cell surface: make way, lysosomes to the rescue. J Cell Sci, 2002. 115(Pt 5): pp. 873-9.

[107] Rizo, J. and J. Xu, The synaptic vesicle release machinery. Annu Rev Biophys, 2015. 44: pp. 339-67. 
[108] Detrait, E., et al., Axolemmal repair requires proteins that mediate synaptic vesicle fusion. J Neurobiol, 2000. 44(4): pp. 382-91.

[109] Detrait, E.R., et al., Plasmalemmal repair of severed neurites of PC12 cells requires $\mathrm{Ca}(2+)$ and synaptotagmin. J Neurosci Res, 2000. 62(4): pp. 566-73.

[110] Fox, M.A. and J.R. Sanes, Synaptotagmin I and II are present in distinct subsets of central synapses. J Comp Neurol, 2007. 503(2): pp. 280-96.

[111] Shen, S.S., et al., Molecular regulation of membrane resealing in 3 T3 fibroblasts. J Biol Chem, 2005. 280(2): pp. 1652-60.

[112] Chakrabarti, S., et al., Impaired membrane resealing and autoimmune myositis in synaptotagmin VII-deficient mice. J Cell Biol, 2003. 162(4): pp. 543-9.

[113] Toops, K.A. and A. Lakkaraju, Let's play a game of chutes and ladders: lysosome fusion with the epithelial plasma membrane. Commun Integr Biol, 2013. 6(4): p. e24474.

[114] Shen, S.S. and R.A. Steinhardt, The mechanisms of cell membrane resealing in rabbit corneal epithelial cells. Curr Eye Res, 2005. 30(7): pp. 543-54.

[115] Rao, S.K., et al., Identification of SNAREs involved in synaptotagmin VII-regulated lysosomal exocytosis. J Biol Chem, 2004. 279(19): pp. 20471-9.

[116] Tardieux, I., et al., Lysosome recruitment and fusion are early events required for trypanosome invasion of mammalian cells. Cell, 1992. 71(7): pp. 1117-30.

[117] Miyake, K. and P.L. McNeil, Vesicle accumulation and exocytosis at sites of plasma membrane disruption. J Cell Biol, 1995. 131(6 Pt 2): pp. 1737-45.

[118] Togo, T., T.B. Krasieva, and R.A. Steinhardt, A decrease in membrane tension precedes successful cell-membrane repair. Mol Biol Cell, 2000. 11(12): pp. 4339-46.

[119] Cooper, S.T. and P.L. McNeil, Membrane repair: mechanisms and pathophysiology. Physiol Rev, 2015. 95(4): pp. 1205-40.

[120] Togo, T. and R.A. Steinhardt, Nonmuscle myosin IIA and IIB have distinct functions in the exocytosis-dependent process of cell membrane repair. Mol Biol Cell, 2004. 15(2): pp. 688-95.

[121] Andrews, N.W., M. Corrotte, and T. Castro-Gomes, Above the fray: surface remodeling by secreted lysosomal enzymes leads to endocytosis-mediated plasma membrane repair. Semin Cell Dev Biol, 2015. 45: pp. 10-7.

[122] Stauber, W.T., Eccentric action of muscles: physiology, injury, and adaptation. Exerc Sport Sci Rev, 1989. 17: pp. 157-85.

[123] Proske, U. and D.L. Morgan, Muscle damage from eccentric exercise: mechanism, mechanical signs, adaptation and clinical applications. J Physiol, 2001. 537(Pt 2): pp. 333-45. 
[124] Takekura, H., et al., Eccentric exercise-induced morphological changes in the membrane systems involved in excitation-contraction coupling in rat skeletal muscle. J Physiol, 2001. 533(Pt 2): pp. 571-83.

[125] Bashir, R., et al., A gene related to Caenorhabditis elegans spermatogenesis factor fer-1 is mutated in limb-girdle muscular dystrophy type 2B. Nat Genet, 1998. 20(1): pp. 37-42.

[126] Liu, J., et al., Dysferlin, a novel skeletal muscle gene, is mutated in Miyoshi myopathy and limb girdle muscular dystrophy. Nat Genet, 1998. 20(1): pp. 31-6.

[127] Anderson, L.V., et al., Dysferlin is a plasma membrane protein and is expressed early in human development. Hum Mol Genet, 1999. 8(5): pp. 855-61.

[128] Bansal, D., et al., Defective membrane repair in dysferlin-deficient muscular dystrophy. Nature, 2003. 423(6936): pp. 168-72.

[129] Pangrsic, T., et al., Hearing requires otoferlin-dependent efficient replenishment of synaptic vesicles in hair cells. Nat Neurosci, 2010. 13(7): pp. 869-76.

[130] Johnson, C.P. and E.R. Chapman, Otoferlin is a calcium sensor that directly regulates SNARE-mediated membrane fusion. J Cell Biol, 2010. 191(1): pp. 187-97.

[131] Reisinger, E., et al., Probing the functional equivalence of otoferlin and synaptotagmin 1 in exocytosis. J Neurosci, 2011. 31(13): pp. 4886-95.

[132] Piccolo, F., et al., Intracellular accumulation and reduced sarcolemmal expression of dysferlin in limb - girdle muscular dystrophies. Ann Neurol, 2000. 48(6): pp. 902-12.

[133] McDade, J.R., A. Archambeau, and D.E. Michele, Rapid actin-cytoskeleton-dependent recruitment of plasma membrane-derived dysferlin at wounds is critical for muscle membrane repair. FASEB J, 2014. 28(8): pp. 3660-70.

[134] Cai, C., et al., Membrane repair defects in muscular dystrophy are linked to altered interaction between MG53, caveolin-3, and dysferlin. J Biol Chem, 2009. 284(23): pp. 15894-902.

[135] Matsuda, C., et al., The C2A domain in dysferlin is important for association with MG53 (TRIM72). PLoS Curr, 2012. 4: p. e5035add8caff4.

[136] Waddell, L.B., et al., Dysferlin, annexin A1, and mitsugumin 53 are upregulated in muscular dystrophy and localize to longitudinal tubules of the T-system with stretch. J Neuropathol Exp Neurol, 2011. 70(4): pp. 302-13.

[137] Cacciottolo, M., et al., Reverse engineering gene network identifies new dysferlin-interacting proteins. J Biol Chem, 2011. 286(7): pp. 5404-13.

[138] Redpath, G.M., et al., Calpain cleavage within dysferlin exon 40a releases a synaptotagminlike module for membrane repair. Mol Biol Cell, 2014. 25(19): pp. 3037-48.

[139] Fuson, K., et al., Alternate splicing of dysferlin C2A confers Ca(2)(+)-dependent and Ca(2)(+)independent binding for membrane repair. Structure, 2014. 22(1): pp. 104-15. 
[140] McDade, J.R. and D.E. Michele, Membrane damage-induced vesicle-vesicle fusion of dysferlin-containing vesicles in muscle cells requires microtubules and kinesin. Hum Mol Genet, 2014. 23(7): pp. 1677-86.

[141] Cocucci, E., et al., Enlargeosome, an exocytic vesicle resistant to nonionic detergents, undergoes endocytosis via a nonacidic route. Mol Biol Cell, 2004. 15(12): pp. 5356-68.

[142] Shtivelman, E., F.E. Cohen, and J.M. Bishop, A human gene (AHNAK) encoding an unusually large protein with a 1.2-microns polyionic rod structure. Proc Natl Acad Sci U S A, 1992. 89(12): pp. 5472-6.

[143] Davis, T.A., B. Loos, and A.M. Engelbrecht, AHNAK: the giant jack of all trades. Cell Signal, 2014. 26(12): pp. 2683-2693.

[144] Borgonovo, B., et al., Regulated exocytosis: a novel, widely expressed system. Nat Cell Biol, 2002. 4(12): pp. 955-62.

[145] Cocucci, E., et al., Enlargeosome traffic: exocytosis triggered by various signals is followed by endocytosis, membrane shedding or both. Traffic, 2007. 8(6): pp. 742-57.

[146] Benaud, C., et al., AHNAK interaction with the annexin 2/S100A10 complex regulates cell membrane cytoarchitecture. J Cell Biol, 2004. 164(1): pp. 133-44.

[147] Schuchman, E.H., Acid sphingomyelinase, cell membranes and human disease: lessons from Niemann-Pick disease. FEBS Lett, 2010. 584(9): pp. 1895-900.

[148] Zha, X., et al., Sphingomyelinase treatment induces ATP-independent endocytosis. J Cell Biol, 1998. 140(1): pp. 39-47.

[149] Idone, V., et al., Repair of injured plasma membrane by rapid Ca2+-dependent endocytosis. J Cell Biol, 2008. 180(5): pp. 905-14.

[150] Gulbins, E. and R. Kolesnick, Raft ceramide in molecular medicine. Oncogene, 2003. 22(45): pp. 7070-7.

[151] van Blitterswijk, W.J., et al., Ceramide: second messenger or modulator of membrane structure and dynamics? Biochem J, 2003. 369(Pt 2): pp. 199-211.

[152] Holopainen, J.M., M.I. Angelova, and P.K. Kinnunen, Vectorial budding of vesicles by asymmetrical enzymatic formation of ceramide in giant liposomes. Biophys J, 2000. 78(2): pp. 830-8.

[153] Corrotte, M., et al., Caveolae internalization repairs wounded cells and muscle fibers. Elife, 2013. 2: p. e00926.

[154] Nabi, I.R. and P.U. Le, Caveolae/raft-dependent endocytosis. J Cell Biol, 2003. 161(4): pp. 673-7.

[155] Nichols, B., Caveosomes and endocytosis of lipid rafts. J Cell Sci, 2003. 116(Pt 23): pp. 470714. 
[156] Nigro, V. and M. Savarese, Genetic basis of limb-girdle muscular dystrophies: the 2014 update. Acta Myol, 2014. 33(3): pp. 1-12.

[157] Trajkovic, K., et al., Ceramide triggers budding of exosome vesicles into multivesicular endosomes. Science, 2008. 319(5867): pp. 1244-7.

[158] Draeger, A. and E.B. Babiychuk, Ceramide in plasma membrane repair. Handb Exp Pharmacol, 2013(216): pp. 341-53.

[159] Wang, S., et al., Endocytic response of type I alveolar epithelial cells to hypertonic stress. Am J Physiol Lung Cell Mol Physiol, 2011. 300(4): pp. L560-8.

[160] Kim, S.C., et al., TRIM72 is required for effective repair of alveolar epithelial cell wounding. Am J Physiol Lung Cell Mol Physiol, 2014. 307(6): pp. L449-59.

[161] Jia, Y., et al., Treatment of acute lung injury by targeting MG53-mediated cell membrane repair. Nat Commun, 2014. 5: p. 4387.

[162] Atanassoff, A.P., et al., Microvesicle shedding and lysosomal repair fulfill divergent cellular needs during the repair of streptolysin O-induced plasmalemmal damage. PLoS One, 2014. 9(2): p. e89743.

[163] Tinevez, J.Y., et al., Role of cortical tension in bleb growth. Proc Natl Acad Sci U S A, 2009. 106(44): pp. 18581-6.

[164] Charras, G.T., et al., Life and times of a cellular bleb. Biophys J, 2008. 94(5): pp. 1836-53.

[165] Dai, J. and M.P. Sheetz, Membrane tether formation from blebbing cells. Biophys J, 1999. 77(6): pp. 3363-70.

[166] Charras, G.T., et al., Non-equilibration of hydrostatic pressure in blebbing cells. Nature, 2005. 435(7040): pp. 365-9.

[167] Cunningham, C.C., Actin polymerization and intracellular solvent flow in cell surface blebbing. J Cell Biol, 1995. 129(6): pp. 1589-99.

[168] Keyel, P.A., et al., Streptolysin O clearance through sequestration into blebs that bud passively from the plasma membrane. J Cell Sci, 2011. 124(Pt 14): pp. 2414-23.

[169] Babiychuk, E.B., et al., Blebbing confers resistance against cell lysis. Cell Death Differ, 2011. 18(1): pp. 80-9.

[170] Gauthier, N.C., et al., Temporary increase in plasma membrane tension coordinates the activation of exocytosis and contraction during cell spreading. Proc Natl Acad Sci U S A, 2011. 108(35): pp. 14467-72.

[171] Morita, E., et al., Human ESCRT and ALIX proteins interact with proteins of the midbody and function in cytokinesis. EMBO J, 2007. 26(19): pp. 4215-27.

[172] Olmos, Y. and J.G. Carlton, The ESCRT machinery: new roles at new holes. Curr Opin Cell Biol, 2016. 38: pp. 1-11. 
[173] Schuh, A.L. and A. Audhya, The ESCRT machinery: from the plasma membrane to endosomes and back again. Crit Rev Biochem Mol Biol, 2014. 49(3): pp. 242-61.

[174] Scheffer, L.L., et al., Mechanism of Ca(2)(+)-triggered ESCRT assembly and regulation of cell membrane repair. Nat Commun, 2014. 5: p. 5646.

[175] Togo, T., Cell membrane disruption stimulates NO/PKG signaling and potentiates cell membrane repair in neighboring cells. PLoS One, 2012. 7(8): p. e42885.

[176] Togo, T., Short-term potentiation of membrane resealing in neighboring cells is mediated by purinergic signaling. Purinergic Signal, 2014. 10(2): pp. 283-90.

[177] Cooper, S.T. and S.I. Head, Membrane injury and repair in the muscular dystrophies. Neuroscientist, 2014. 21(6): p. 653-68.

[178] Allen, D.G., N.P. Whitehead, and S.C. Froehner, Absence of dystrophin disrupts skeletal muscle signaling: Roles of $\mathrm{Ca} 2+$, reactive oxygen species, and nitric oxide in the development of muscular dystrophy. Physiol Rev, 2016. 96(1): pp. 253-305.

[179] Clark, A.G., et al., Integration of single and multicellular wound responses. Curr Biol, 2009. 19(16): pp. 1389-95.

[180] Russo, J.M., et al., Distinct temporal-spatial roles for rho kinase and myosin light chain kinase in epithelial purse-string wound closure. Gastroenterology, 2005. 128(4): pp. 987-1001.

[181] Tamada, M., et al., Two distinct modes of myosin assembly and dynamics during epithelial wound closure. J Cell Biol, 2007. 176(1): pp. 27-33.

[182] Grasso, S., J.A. Hernandez, and S. Chifflet, Roles of wound geometry, wound size, and extracellular matrix in the healing response of bovine corneal endothelial cells in culture. Am J Physiol Cell Physiol, 2007. 293(4): pp. C1327-37.

[183] Klarlund, J.K., Dual modes of motility at the leading edge of migrating epithelial cell sheets. Proc Natl Acad Sci U S A, 2012. 109(39): pp. 15799-804.

[184] Ravasio, A., et al., Gap geometry dictates epithelial closure efficiency. Nat Commun, 2015. 6: p. 7683.

[185] Brugués, A., et al., Forces driving epithelial wound healing. Nat Phys, 2014. 10(9): pp. 683-90.

[186] Wu, M. and M. Ben Amar, Growth and remodelling for profound circular wounds in skin. Biomech Model Mechanobiol, 2015. 14(2): pp. 357-70. 
